\title{
Trayectorias interrumpidas: motivos de estudiantes universitarios para suspender temporalmente sus estudios durante la pandemia
}

\author{
Frida Díaz-Barriga-Arceo, Javier Alatorre-Rico y Fernando Castañeda-Solís
}

\begin{abstract}
RESUMEN
La pandemia por Covid-19 ha afectado la continuidad de las trayectorias escolares de muchos estudiantes que han tenido que suspender sus estudios temporal o definitivamente. En el caso de la Universidad Nacional Autónoma de México (UNAM), el Secretario General llegó a plantear en 2020 que un 20\% de estudiantes estaba en riesgo de abandonar estudios por la pandemia, mientras que para 2021 se incrementó en 228\% el estudiantado que solicitó suspensión temporal de sus estudios. A fin de identificar los motivos aducidos por el estudiantado para solicitar ante el Consejo Técnico de su entidad una suspensión temporal de estudios, se condujo un estudio mixto convergente donde se analizan los motivos de 268 estudiantes de la licenciatura en Psicología de la Facultad de Psicología de la UNAM, sistemas abierto y escolarizado, para suspender temporalmente sus estudios. El propósito es comprender, desde la voz del estudiantado, la problemática que han estado vivenciando durante la pandemia sin poder lograr continuidad con la trayectoria teórica tipificada por la administración escolar. Los resultados indican la interrelación de factores asociados a las condiciones socioeconómicas o laborales del alumnado y su familia, responsabilidades y problemas en el hogar, carencia de infraestructura tecnológica apropiada, problemas de salud y emocionales, condiciones educativas y rezago académico previo, así como insatisfacción y desmotivación respecto a la educación en línea recibida y a la reducción del semestre escolar. Se discuten propuestas de atención y prevención al abandono de los estudios universitarios durante la pandemia.
\end{abstract}

Palabras clave: trayectoria escolar, educación superior, rezago escolar, experiencia de los estudiantes, desarrollo humano, pandemia Covid-19, México.

Frida Díaz-Barriga-Arceo

diazfrida@prodigy.net.mx Mexicana. Doctora en Pedagogía, Facultad de Filosofía y Letras, Universidad Nacional Autónoma de México (UNAM). Profesora titular de tiempo completo, Facultad de Psicología, UNAM. Temas de investigación: currículo y socioconstructivismo, diseño educativo y aprendizaje situado, TIC en educación. ORCID: https://orcid.org/0000-0001-8720-1857.

Javier Alatorre-Rico

alatorrerico@yahoo.com.mx Mexicano. Maestro en Psicología de la Educación y Desarrollo, Facultad de Psicología, Universidad Nacional Autónoma de México (UNAM). Técnico académico y Profesor de Asignatura, Facultad de Psicología, UNAM. Temas de investigación: formación de profesores de ciencias del nivel medio superior con base en la teoría sociocultural. ORCID: https://orcid.org/0000-0002-4133-7676. Investigador Nacional Nivel 3 del CONACYT e integrante del Grupo de Investigación en Docencia, Diseño Educativo y TIC (GIDDET), Facultad de Psicología, UNAM. Temas de investigación: educación inclusiva y ocio humanista en personas con discapacidad y en situación de vulnerabilidad. ORCID: https://orcid.org/0000-0002-8190-5789. 
Trajetórias interrompidas: motivos de estudantes universitários para suspender temporalmente seus estudos durante a pandemia

\title{
RESUMO
}

A pandemia por Covid-19 tem afetado a continuidade das trajetórias escolares de muitos estudantes que têm tido que suspender seus estudos temporal ou definitivamente. No caso da Universidad Nacional Autónoma de México (UNAM), o Secretário Geral chegou a dizer em 2020 que 20\% dos estudantes estavam em risco de abandonar os estudos por causa da pandemia, já em 2021 aumentou a 228\% o número de estudantes que solicitou suspensão temporal de seus estudos. A fim de identificar os motivos declarados pelos estudantes para solicitar ao Conselho Técnico de sua entidade uma suspensão temporal de estudos, se fez um estudo misto convergente onde se analisam os motivos de 268 estudantes da licenciatura em Psicologia da Facultad de Psicología da UNAM, sistemas aberto e escolarizado, para suspender temporalmente seus estudos. O propósito é compreender, a partir da voz dos estudantes, a problemática que têm vivenciado durante a pandemia sem poder dar continuidade à trajetória teórica tipificada pela administração escolar. Os resultados indicam a inter-relação de fatores associados às condições socioeconómicas ou laborais dos alunos e suas famílias, responsabilidades e problemas no lar, carência de infraestrutura tecnológica apropriada, problemas de saúde e emocionais, condições educativas e atraso acadêmico prévio, assim como insatisfação e desmotivação com respeito à educação a distância recebida e à redução do semestre escolar. Se discutem propostas de atenção e prevenção ao abandono dos estudos universitários durante a pandemia.

Palavras chave: trajetória escolar, educação superior, atraso escolar, experiência dos estudantes, desenvolvimento humano, pandemia Covid-19, México.

\section{Interrupted trajectories: university students' reasons for temporarily suspending their studies during the pandemic}

\begin{abstract}
The Covid-19 pandemic has affected the continuity of the educational trajectories of many students who have had to suspend their studies temporarily or permanently. In the case of the National Autonomous University of Mexico (UNAM), the General Secretary's office stated in 2020 that $20 \%$ of students were at risk of dropping out of school due to the pandemic, while by 2021 the number of students requesting temporary suspension of their studies increased by $228 \%$. In order to identify the reasons put forward by the student body for submitting to the Technical Council of their entity a temporary suspension of studies, a mixed convergent study was conducted in which the causes given by 268 students of the Psychology degree of the Faculty of Psychology of the UNAM, both open and attendance systems, for temporarily suspending their studies are analyzed. The purpose is to understand, based on the voice of the students, the problems they have been experiencing during the pandemic without being able to achieve continuity with the theoretical trajectory typified by the school administration. The results indicate the interrelation of factors associated with socioeconomic or labor conditions of the students and their families, responsibilities and problems at home, lack of appropriate technological infrastructure, health and emotional problems, educational conditions and prior academic lag, as well as dissatisfaction and demotivation regarding the online education received and the reduction of the school semester. Proposals for attention and prevention of college dropout during the pandemic are discussed.
\end{abstract}

Key words: school trajectory, higher education, school dropout, student experiences, human development, Covid-19 pandemic, Mexico.

Recepción: 05/07/21. Aprobación: 18/10/21. 


\section{Estado de la cuestión: efectos de la pandemia y riesgo de abandono escolar}

Uno de los mayores retos durante y después de la pandemia y confinamiento por Covid-19 se relaciona con la necesidad de garantizar la continuidad de las trayectorias educativas de los educandos en América Latina y el Caribe. En primera instancia, nuestra región es la más desigual del planeta: "19\% más desigual que el África Subsahariana, 37\% más desigual que el Este Asiático y 65\% más desigual que los países desarrollados" (Cuenca, 2012: 81); esto se traduce en un menor rendimiento escolar asociado a mayor desigualdad en el ingreso de la población. Esta situación se hace crítica en la pandemia; desde la perspectiva de la UNESCO (2021), en una reciente encuesta con 18 países de la región, México incluido, concluyó que enfrentamos una continuidad educativa con efectividad incierta y profundización de las desigualdades, con amenaza de un considerable aumento en la desvinculación educativa y en la exclusión de la escolaridad de determinados colectivos, sobre todo de aquellos con condiciones socioeconómicas precarias, sin acceso a las tecnologías digitales, que habitan en zonas rurales o marginadas o que tienen alguna discapacidad. De hecho, esta encuesta muestra que los tres principales retos se ubican en el aumento en el abandono escolar, la pérdida de aprendizajes y la agudización de las inequidades en el aprendizaje asociado a un fuerte impacto económico en las instituciones educativas. Se postula la necesidad de priorizar en 2021 la realización de diagnósticos pedagógicos contextualizados sobre los efectos de la pandemia en los sistemas educativos, así como un seguimiento cercano de quienes se han desvinculado de sus estudios.

Respecto al caso concreto de la educación universitaria, la preocupación por la suspensión y el abandono de estudios es patente. A comienzos de septiembre de 2020, Leonardo Lomelí Vanegas titular de la Secretaría General de la Máxima Casa de Estudios de la Nación, informó que el $20 \%$ de la matrícula de la institución, cerca de 72000 estudiantes de los niveles bachillerato y licenciatura, estaba en peligro de darse de baja o abandonar temporalmente sus estudios (Moreno, 2020). Con posterioridad, en el análisis realizado por Ríos (2021) y con base en estadísticas de la UNAM del 2020, se reporta que 7700 alumnos de bachillerato y licenciatura habían suspendido sus estudios temporalmente y que esta cifra resulta 229\% más alta que la registrada en 2019, cuando fueron 2343 alumnos los que interpusieron dicha solicitud. Según la autora, el $90.1 \%$ de quienes solicitaron dicha interrupción cursan alguna licenciatura. Por otra parte, el Programa de Naciones Unidas para el Desarrollo (PNUD, 2020) estima que, a nivel nacional, en 2021 y asociado a la pandemia, desertarán 593000 universitarios y 38567 estudiantes de posgrado.

Ante la necesidad de conocer la situación del alumnado universitario que decide suspender sus estudios durante la pandemia, en el estudio que se presenta a continuación y teniendo como referencia la concepción de lo que implica la interrupción de una trayectoria escolar, se analizan los motivos que aducen los y las estudiantes de la licenciatura en Psicología de la Facultad de Psicología de la UNAM que solicitaron suspensión temporal de sus estudios.

En la tónica de realizar diagnósticos que permitan conocer los retos que están viviendo los estudiantes universitarios durante la pandemia, en este estudio se analizan dichos motivos y se identifican los factores que condicionan la interrupción de las trayectorias escolares en función de ciertas características de la población estudiantil, así como de diversos factores sistémicos asociados al contexto familiar, social e institucional. La intención es comprender, desde la voz y necesidades del alumnado y desde su papel como actores del currículo, las barreras que han enfrentado en la pandemia y los han conducido a interrumpir su trayectoria escolar. Esta información constituye un insumo de interés para plantear el tipo de apoyos que la institución puede ofrecerles para potencializar su retorno y no dejar su licenciatura trunca. 
De particular relevancia será entender el impacto de la pandemia y el confinamiento en los jóvenes estudiantes. En algunas investigaciones con estudiantes universitarios mexicanos se muestra que la pandemia evidenció o exacerbó las profundas desigualdades existentes. El impacto de la pandemia resulta diferenciado en función del género, nivel socioeconómico, origen étnico, situación laboral, responsabilidades familiares o dependientes económicos. En la Universidad de Guadalajara Pérez-Mora y Moreno (2021) encuentran que las condiciones de aislamiento y restricciones que impuso la pandemia afectaron más a las mujeres, a estudiantes con discapacidades, de origen indígena y de bajo nivel socioeconómico, que reportaron mayor afectación en su avance académico, dificultad para aprender y un alto nivel de estrés. En el caso de estudiantes de la Universidad Autónoma de Chiapas, González-Velázquez (2020) reporta una disminución de la motivación y del rendimiento académico, así como un aumento de la ansiedad y dificultades familiares, principalmente en los estudiantes de escasos recursos socioeconómicos. Sin embargo, el interés de nuestro estudio reside en analizar si estos u otros factores fueron determinantes en la toma de decisiones de aquellos alumnos o alumnas que decidieron interrumpir sus trayectorias escolares durante la pandemia, cuestión poco reportada todavía en la literatura nacional.

\section{Las trayectorias escolares: apuntes para su estudio en pandemia}

El estudio de las trayectorias escolares del estudiantado comenzó a cobrar un interés particular en la primera década de este siglo, sobre todo en lo concerniente a lo que Terigi (2007) denomina desacoplamiento entre la trayectoria personal del estudiante con relación al recorrido esperado por el sistema. Dicha situación, considerada un problema de magnitud creciente, ha sido reconceptualizada de problema individual a problema sistémico, que debe ser atendido con amplitud en la adopción de enfoques explicativos, a la par que concebirse como parte de los estudios sobre infancia, adolescencia y juventud en el contexto latinoamericano.

El concepto de trayectoria "centra su atención en la interpretación de fenómenos sociales a través del tiempo" (Briscioli, 2017: 2). Para esta autora, cuando se habla de trayectoria en el ámbito educativo, las trayectorias escolares del alumnado (school pathways) a lo largo y ancho del sistema, permiten articular las interrelaciones existentes entre el contexto socioeducativo e institucional y el voluntarismo o agencia del sujeto de la educación con referencia a un proyecto de vida y escolaridad, que lo confrontará con alcances y restricciones.

La trayectoria escolar de un estudiante implica un recorrido en construcción permanente y "va mucho más allá de la idea mecánica de acumulación de grados o certificados escolares, regulados por un trayecto estandarizado en un programa o plan de estudios" (Díaz Barriga, López y López, 2020: 5). Como instrumento analítico que permite comprender los procesos formativos en el espacio-tiempo, la noción de trayectoria escolar conduce a un acercamiento a procesos como la conformación de la identidad del aprendiz, la lógica con que un sujeto (actor social dotado de agencia) intenta trazar su propio itinerario de aprendizaje o las posibilidades que tiene de aprovechar los recursos del entorno para satisfacer sus necesidades e intereses de aprendizaje. En el análisis de una trayectoria es importante identificar los motivos y metas, las rutas de aprendizaje por las que pasa una persona en diferentes escenarios y tiempos, las redes de apoyo de que dispone, los obstáculos que enfrenta, entre otros. Los autores antes citados coinciden en que es relevante identificar los factores contextuales (sociohistóricos, económicos, familiares), la dinámica del ethos de la institución escolar en cuanto impone restricciones a la trayectoria ideal y posible del estudiantado, las características de la gestión del proyecto curricular que 
influyen en la posibilidad de conformar trayectorias personalizadas de aprendizaje, ajustadas a intereses y necesidades en distintos tramos formativos.

Analizar la trayectoria de un estudiante no puede restringirse, según Nicastro y Greco (2009: 24), "a consignar la sumatoria de sus pasos por los distintos niveles del sistema" con relación a un perfil tipificado y prescrito en el plan de estudios. Se trata más bien de "un complejo entramado de aspectos o esferas de la vida de los sujetos que participan en la delimitación de un recorrido o itinerario posible" (Toscano, Briscione y Morrone, 2015: 1), donde cobra relevancia el análisis conjunto de la dimensión personal-subjetiva e institucional-social.

Un aporte relevante al tema que nos ocupa proviene de Casal, García, Merino y Quesada (2006), quienes conciben a la juventud como un tramo biográfico y analizan la inserción social y profesional de los jóvenes desde las categorías de itinerario y trayectoria. El itinerario da cuenta de los sucesos y hechos puntuales de la vida de la o el joven en un determinado contexto hasta el momento presente, permite identificar la coyuntura existente, así como las expectativas y decisiones que ha hecho. A su vez, el itinerario permite avizorar rumbos probables en función de factores que pueden operar a favor o en contra. Al respecto, plantean que hay sucesos que producen cierta "cristalización social" dada su escasa reversibilidad, como sería el caso del fracaso escolar o el abandono de la formación sin titulación, aunados a la desigualdad de oportunidades: "los itinerarios y las trayectorias tienen un vínculo con la estructura social: no son independientes de las clases sociales ni del género, ni de la etnia ni de las migraciones" (ibid., 2006: 13).

Por otro lado, para Terigi (2007) es importante distinguir entre trayectorias teóricas y reales. Las trayectorias teóricas plantean una progresión curricular lineal, asociada a la gestión escolar, de un sistema por niveles y periodicidades fijas, anuales o semestrales; es decir, se establece de manera fija el ritmo de adquisición de los aprendizajes y su acreditación mediante evaluaciones en un periodo determinado. La evidencia indica que muchos estudiantes requieren de más tiempo para concluir un periodo formativo y que no egresan en la cohorte a la que pertenecen. La concepción institucional de las trayectorias estudiantiles acoplada a esta visión teórica de trayectoria (ideal, lineal, única) pretende gestionar administrativamente y de forma eficiente un sistema masificado, ajustado a medidas estadísticas de rutas y tiempos promedio óptimos que se pautan en los calendarios de los ciclos escolares. En el caso de interrupciones o rupturas a dicha trayectoria teórica, la normativa institucional decreta rezago o fracaso escolar, imputable habitualmente al estudiante en cuestión.

Terigi (2007: 4) denomina "trayectorias no encauzadas" al hecho de que "muchos niños y jóvenes transitan su escolaridad de modos heterogéneos, variables y contingentes". En las instituciones éstos pasan a la categoría de "irregulares" desde el punto de vista de la administración escolar, independientemente de que los estudios de psicología del aprendizaje y desarrollo hayan estipulado la diversidad de ritmos de aprendizaje, capacidades cognitivas o condiciones personales y sociales que presentan. Así, la etiqueta de "irregular" contribuye a estigmatizar más al alumnado que no se ajusta a la trayectoria teórica o ideal en un plan de estudios, por lo que tal condición se interpreta como falta de capacidad o negligencia.

Por el contrario, desde la filosofía de la educación inclusiva y la justicia social (Echeita, 2020), se cuestiona dicha perspectiva hegemónica y "normotípica" que excluye la diversidad que caracteriza al estudiantado, sobre todo por el riesgo de exclusión escolar que implica en tiempos de pandemia. La gestión y acompañamiento de las trayectorias escolares del estudiantado debe entenderse desde los enfoques educativos centrados en el aprendizaje y la educación inclusiva. 
Entre otras cuestiones, hay que dilucidar si el traslado de la educación presencial a la educación a distancia y virtual ha contribuido o no a la continuidad de las trayectorias personales del estudiantado. En el Congreso Latinoamericano de Comunicaciones celebrado en Córdoba, Argentina en junio de 2019, se informó que "el $45 \%$ de los latinoamericanos no tiene acceso a los servicios derivados de la conectividad digital, tales como telemedicina, teleducación, gobierno en línea y banca electrónica, entre otros" (Corporación Andina de Fomento (CAF), 2019, párr. 3). En el caso de México, la Encuesta Nacional sobre Disponibilidad y Uso de Tecnologías de la Información en los Hogares (ENDUTIH) del 2019, realizada por el Instituto Nacional de Estadística y Geografía (INEGI), mostró que el $43 \%$ de los hogares en el país carece de algún tipo de conexión a internet. De ahí que era previsible que casi la mitad del estudiantado no podría acceder a la educación virtual.

Uno de los mayores saldos de la pandemia es el riesgo en la ruptura de la continuidad de las trayectorias escolares durante y después de ésta. El riesgo de la gran desvinculación educativa que se espera en América Latina y el Caribe, se verá asociado a un retroceso en el desarrollo humano de las personas y de la región misma, dado que tal desarrollo se estima en función del nivel de ingreso, la salud y la educación a los que se tiene acceso (CEPALUNESCO, 2020).

Por otro lado, también es importante entender el impacto psicológico y socioemocional de la pandemia en las comunidades educativas, sobre todo en lo que atañe al riesgo de discontinuidad en las trayectorias escolares que puede derivar en abandono de los estudios, así como en el retroceso de la atención al alumnado en situación de vulnerabilidad.

\section{Método}

\section{Planteamiento del problema}

Con base en la literatura antes citada, la desvinculación educativa afecta la experiencia vital de los jóvenes universitarios que tienen que interrumpir sus estudios, afecta sus posibilidades de aprendizaje a lo largo de la vida y los aprendizajes requeridos para acceder a mejores condiciones de existencia, en síntesis, impacta negativamente en su desarrollo humano. Asimismo, les impide eventualmente asumir su participación responsable en sociedad ejerciendo una profesión para la cual se haya asegurado una sólida preparación.

En diversos estudios con población estudiantil que cursa estudios universitarios en países latinoamericanos, se han identificado las problemáticas antes mencionadas en los análisis regionales de CEPALUNESCO (2020) y se encuentra que hay colectivos con mayor riesgo de interrupción o rezago en sus estudios en los tiempos de pandemia por Covid-19. En algunas investigaciones se encuentra que existe una compleja interrelación de factores socioeconómicos y de cuestiones propias de las formas de gestión de la emergencia en las universidades, en conjunción con aspectos de índole personal y subjetiva que han afectado las trayectorias del alumnado y su condición personal y afectiva (González-Velázquez, 2020; Infante, Peláez y Giraldo, 2021; Lozano, Fernández, Figueredo y Martínez, 2020; Pequeño et al., 2020; Román, 2020). El tema de fondo es la evidencia de la desigualdad social y la brecha digital imperante. Respecto al acceso a tecnologías digitales para la educación en línea durante la pandemia, la Encuesta de Movilidad de la UNAM (junio de 2020), con una muestra de 33203 estudiantes de 91 escuelas y facultades, encontró que el 23\% dijo no tener acceso a internet en sus hogares y $25 \%$ no contar con un lugar adecuado para estudiar. Acerca del equipo de cómputo del que disponen, $34 \%$ no tiene laptop, el 82\% no dispone de una tableta, mientras que el $97 \%$ dijo tener acceso a un teléfono celular. Los datos evidencian que un número relevante de estudiantes universitarios no tiene el acceso y condiciones adecuadas para estudiar en línea durante el confinamiento por la pandemia, lo que implica un asunto de equidad educativa y justicia social. 
Con la intención de abonar a la comprensión de la problemática antes descrita, así como para contribuir al tipo de diagnósticos situacionales que permitan comprender desde la voz del estudiantado la problemática que están viviendo en pandemia y que les conduce a suspender sus estudios, se realizó el presente estudio, cuyo foco es el análisis de los motivos planteados por los y las jóvenes cuando solicitan formalmente dicha suspensión. No hemos encontrado estudios similares en la literatura ni en la institución de interés por lo cual consideramos que es un trabajo exploratorio que busca desvelar el por qué se interrumpen las trayectorias escolares durante la pandemia.

La principal aportación de un estudio como éste es el reconocimiento de los factores asociados a las trayectorias reales del estudiantado que provocan discontinuidad respecto a las trayectorias teóricas o ideales esperadas y colocan al estudiante en la encrucijada del abandono temporal (o tal vez definitivo) de sus estudios universitarios. El estudio se inscribe en la lógica de la investigación sobre los actores del currículo (Barrón y Díaz Barriga, 2016), en cuanto se busca recuperar desde la voz de éstos, en un contexto y situación acotadas, los motivos que animan sus acciones en función de su situación de vida cotidiana. En esta línea de estudios, los factores biográficos y contextuales cobran relevancia bajo el supuesto que lo personal es político. El eventual beneficio de este tipo de estudios reside en que las instituciones educativas asuman la responsabilidad de generar políticas y programas educativos para la prevención y atención del rezago o interrupción en las trayectorias de aprendizaje en el nivel universitario.

\section{Pregunta de investigación y objetivos}

La pregunta de investigación se planteó en términos de ¿Cuáles son los motivos que conducen a la suspensión temporal de estudios en los estudiantes de la licenciatura en Psicología durante la pandemia por Covid-19?

\section{Objetivos}

- Identificar, desde la perspectiva y vivencia del alumnado, cuáles son los motivos que les conducen a tomar la decisión de suspender temporalmente sus estudios universitarios durante la pandemia por Covid-19.

- Analizar de qué manera intervienen diversos factores personales, académicos y contextuales, en la discontinuidad e interrupción de la trayectoria académica estudiantil durante la pandemia.

- Proponer diversas medidas y apoyos para la recuperación y continuidad de la trayectoria del estudiantado que ha decidido suspender sus estudios universitarios en el contexto situado en la entidad académica donde cursan una licenciatura universitaria.

\section{Tipo de estudio y análisis realizado}

Se trata de un estudio mixto, de tipo convergente o paralelo, en el cual se analizan de forma concurrente datos cuantitativos y cualitativos (Creswell y PlanoClark, 2018: 65), donde "ambos tipos de resultados se comparan con la intención de obtener una comprensión más completa del problema".

La información fue obtenida de los oficios turnados por las y los interesados al solicitar el trámite respectivo ante el Consejo Técnico. Los autores de este artículo, académicos e investigadores del claustro de Psicología de la Educación, quienes conducen una línea de estudios sobre vulnerabilidad académica e inclusión, acordaron con las autoridades escolares analizar esta información para proponer apoyos al alumnado. Se elaboró una base de datos en Excel con los datos de los 268 casos del presente estudio y se realizó en principio un análisis de contenido cualitativo de los escritos del alumnado, que permitió la conformación de diversas categorías, respecto a las cuales se computaron a continuación frecuencias y porcentajes y se seleccionaron algunas respuestas ilustrativas del discurso de los y las jóvenes. A los 
investigadores sólo se nos proporcionaron los párrafos con las justificaciones planteadas y los datos de sexo, semestre, promedio, sistema escolar, etcétera; en ningún caso se tuvo acceso al nombre $\mathrm{u}$ otros datos personales y el análisis procedió de forma anónima respecto a la identidad del alumnado. No se tuvo la posibilidad de profundizar más allá de lo escrito en la solicitud de cada estudiante ni se tuvo acceso a otro tipo de información que la aquí reportada. Es decir, la información-insumo está acotada a la justificación o exposición de motivos planteada por escrito en dicha solicitud, que abarca entre uno y tres párrafos. Lo relevante es que la información fue escrita de manera libre, con autenticidad, desde la propia voz de las y los solicitantes. La finalidad, aparte de abonar a la comprensión de la problemática del alumnado universitario durante la pandemia, era proponer algunas medidas a la directiva de la facultad para evitar el abandono definitivo de los estudios universitarios y prever casos futuros.

\section{Contexto y características de los y las estudiantes que suspendieron estudios}

La suspensión temporal de estudios en la UNAM está prevista hasta por dos semestres en los términos que marca el artículo 23 del Reglamento General de Inscripciones (data de 1997) de la propia universidad. De esta manera el estudiantado puede suspender temporalmente sus estudios sin afectar los límites de tiempo establecidos para estar inscrito en la UNAM y completar sus estudios. Los estudiantes deben turnar su solicitud al Consejo Técnico de la respectiva facultad o escuela con una exposición de motivos o justificación y dicho órgano colegiado toma una decisión, en general positiva, pues esto se considera un derecho que asiste al alumnado. En alguna medida, permite paliar los efectos negativos que desde el punto de vista administrativo puede tener la discontinuidad en la trayectoria curricular que prescribe el currículo en los tiempos que para ello están acotados.

En todo caso, la suspensión temporal de los estudios indica que el o la estudiante ha llegado a un punto en que no puede o no se siente en disposición de continuar estudiando la licenciatura en cuestión, lo que incrementa el riesgo de que más adelante no pueda retomar sus estudios y consolidar su trayecto profesional.

En el caso de la Facultad de Psicología, se condujo el análisis con estudiantes de las dos modalidades, presencial y abierta, que solicitaron la suspensión anual o semestral entre los periodos 2021-1 a 2022-1.

Como se puede observar en la gráfica 1, más mujeres $(68 \%)$ que hombres $(32 \%)$ solicitaron suspensión temporal, aunque hay que considerar la feminización del estudiantado de la Facultad, que corrobora la relación 7/3.

En la gráfica 2 se encuentra que en una proporción relativamente similar piden la suspensión temporal los estudiantes del Sistema de Universidad Abierta (SUA) $(47 \%)$ y quienes cursan el sistema escolarizado (53\%).

Destaca que en su gran mayoría son estudiantes "irregulares" (79\%) en lo concerniente a su avance curricular. Es decir, no han acreditado algunas asignaturas en el tiempo curricular pautado o no las han cursado aún, tomando en cuenta el semestre en que se encuentran. Sus trayectorias son discontinuas, no han seguido la ruta teórica ideal estipulada en el plan de estudios. No obstante, un 21\% mantienen una trayectoria continua y la institución los considera alumnos "regulares" (gráfica 3). 
Gráfica 1. Solicitudes de suspensión temporal por sexo del alumnado

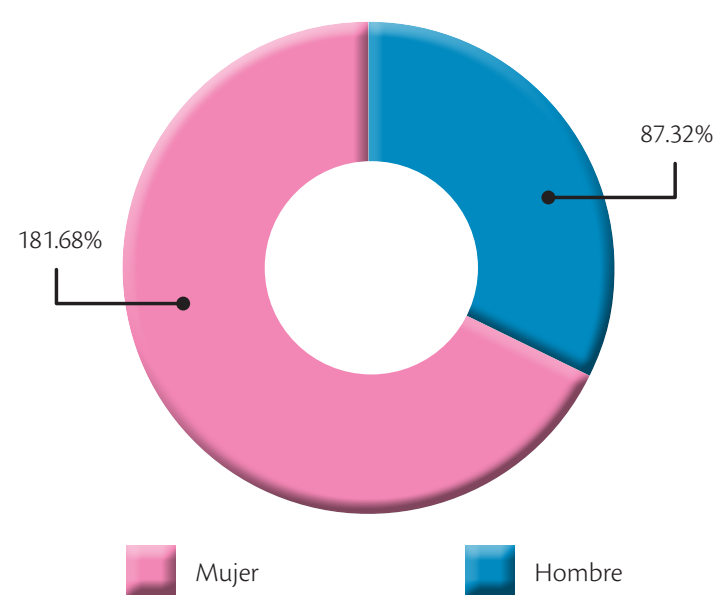

Fuente: elaboración propia con base en la investigación.
Gráfica 2. Solicitudes de suspensión temporal por sistema (escolarizado/abierto)

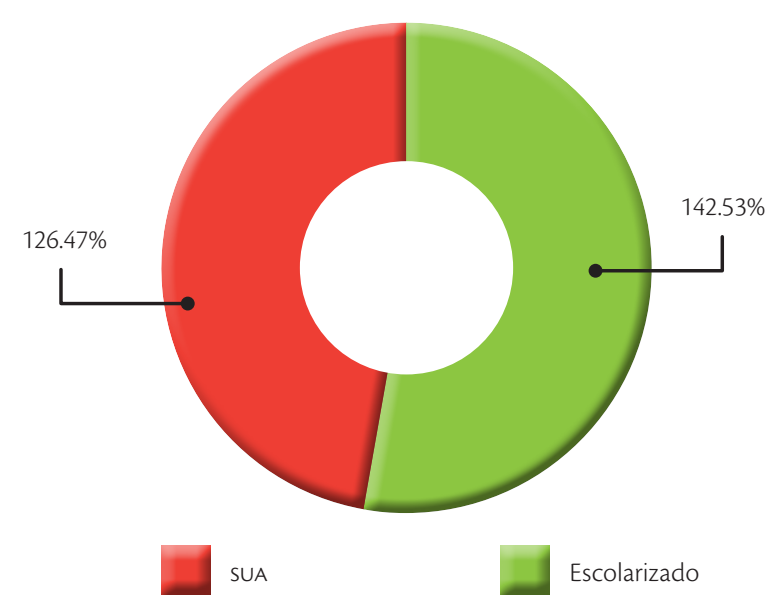

Fuente: elaboración propia con base en la investigación.

Gráfica 3. Situación académica del alumnado que solicitó la suspensión temporal de estudios

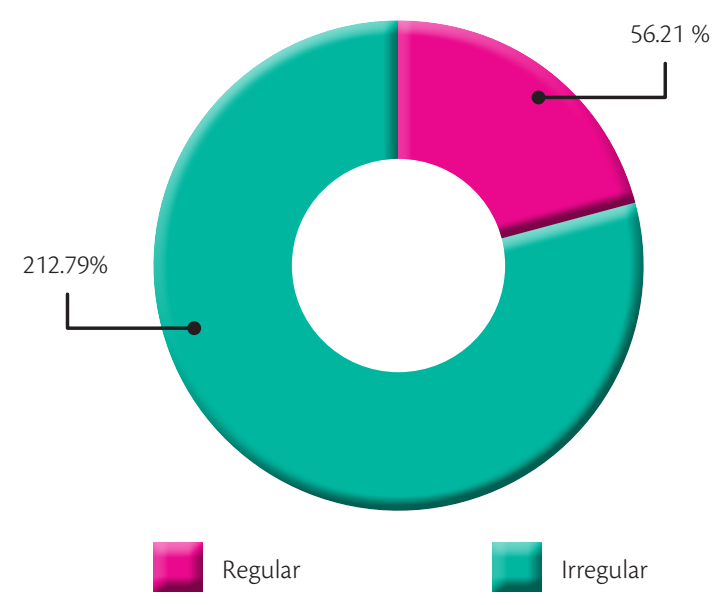

Fuente: elaboración propia con base en la investigación. 
Otro indicador para entender la trayectoria de un estudiante se relaciona con el promedio académico, aun tomando en cuenta que existe controversia en su significado. En la gráfica 4, se muestra el promedio general que tienen estos alumnos. Hay que destacar que cerca de la mitad $(49 \%)$ tiene un promedio entre 8 y 8.9 , mientras que el 15\% tiene un promedio superior a 9 (en una escala de 10), por lo que puede decirse que dos tercios de los solicitantes son estudiantes con un "buen rendimiento escolar" en términos de sus calificaciones, no obstante que muestran una trayectoria escolar discontinua. El resultado es de interés porque se suele asociar la discontinuidad en los estudios con un bajo promedio, situación cuestionable por lo menos en esta población.

Hasta el momento en que sucedió la pandemia, esta población no se había visto en la necesidad de suspender estudios. Es decir, la gran mayoría solicitó por primera vez $(93 \%)$ la suspensión temporal de estudios, ya sea semestral $(56 \%)$ o anual $(44 \%)$. Por ello consideramos que los motivos aducidos por los estudiantes, aunque tal vez podrían estar presentes antes de la pandemia, emergieron o se exacerbaron con intensidad durante ésta, de manera tal que obstaculizaron la continuidad educativa y los llevaron a la decisión de suspender sus estudios.

Otro dato de interés es que los semestres en que más se solicitó la suspensión fueron los dos más recientes, por lo que las condiciones asociadas a la pandemia, los dos paros (del movimiento feminista demandando alto a la violencia de género y de los profesores de asignatura demandando su salario), así como situaciones referidas a insatisfacción con la enseñanza virtual o la reducción de semanas del semestre más reciente, incrementaron la discontinuidad. Fueron 90 alumnos (34\%) los que pidieron suspensión temporal anual para el ciclo 2021-2 a 2022-1, mientras que 63 (24\%) pidieron suspender el semestre 2021-2.

Otro dato relevante es que quienes más solicitaron la suspensión de estudios eran estudiantes que tenían el 25\% de avance en créditos de la carrera, mientras que el alumnado con un avance sustancial en sus estudios (más del 75\% de créditos) son los que menos solicitaron dicha suspensión. Respecto al semestre que estaban cursando cuando solicitaron este trámite, se encontró que los estudiantes de $4^{\circ}\left(26^{\%} \%\right)$, $2^{\circ}(21 \%)$ y $6^{\circ}(17 \%)$ semestres, en ese orden, fueron los que más recurrieron a este trámite.

\section{Gráfica 4. Solicitudes de suspensión temporal por rango de promedio escolar}

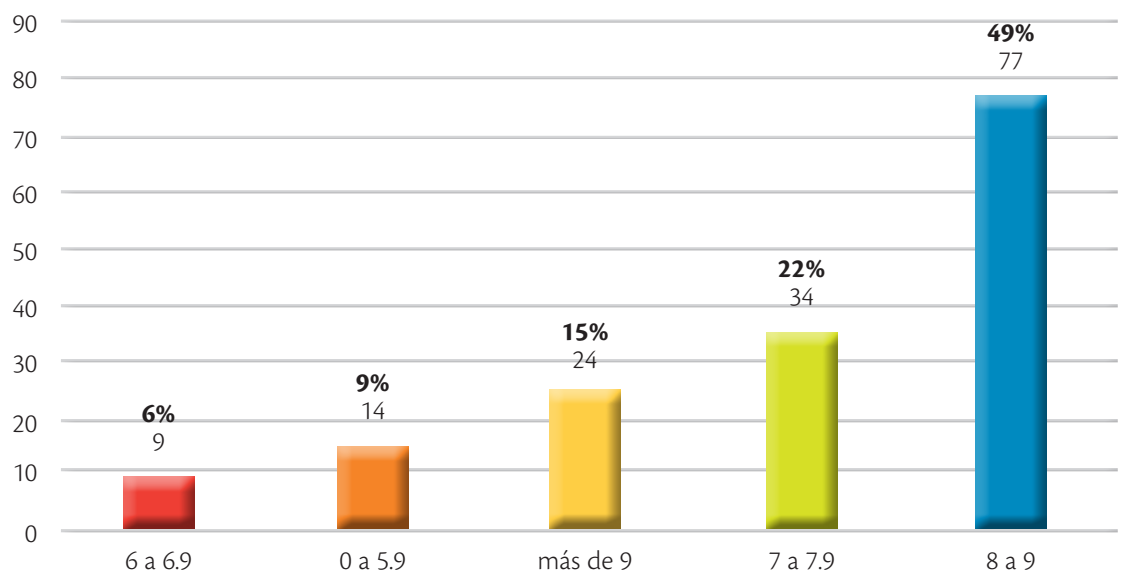




\section{Resultados}

Principales motivos de suspensión temporal

En principio se realizó un análisis cualitativo de contenido respecto a los motivos que los estudiantes aducían en sus solicitudes al solicitar la baja temporal. Con base en este análisis se elaboró un mapa de categorías de respuesta y se identificaron algunas dimensiones. En la figura 1 se presenta dicho mapa.

Como se observa, los principales motivos para suspender estudios son los siguientes: las condiciones económicas y laborales, ya sea personales o familiares; la escasa infraestructura tecnológica con la que cuentan en el hogar y las dificultades en el acceso a los servicios digitales; las condiciones familiares y la dinámica o exigencias en el hogar; las condiciones de salud que presentan ellos mismos o algún familiar cercano, sea por Covid-19 u otra enfermedad; la situación socioemocional que enfrentan; las condiciones de su formación académica y trayectoria escolar previa que les impiden continuar. La drástica reducción de semanas del semestre 2022-1, la suspensión de clases por los dos paros en la entidad, la inconformidad con enseñanza en línea, fueron aspectos que detonaron el incremento de solicitudes de suspensión.

Por lo general, el alumnado no expresaba sólo un motivo, sino que solía mencionar varias situaciones problema. Así, cuando se procedió a la cuantificación de los motivos tomando en cuenta el mapa de categorías propuesto, se observa que las frecuencias de respuesta sobrepasan el número de estudiantes.

Un ejemplo que ilustra la multideterminación de situaciones que conduce a la suspensión, es el siguiente (se indica el número del caso analizado):

Mis ingresos económicos han bajado y dificulta tener una buena conexión a internet en el lugar actual donde estoy, mis familiares tienen un estado de salud muy delicado y debo estar pendiente para cubrir sus necesidades, mi estado emocional está totalmente disperso y no puedo rendir al máximo (S125).
En la gráfica 5 se cuantifican los principales motivos de las y los estudiantes para suspender sus estudios en términos de porcentajes y frecuencias. Como se puede observar, el motivo principal son las condiciones económicas del alumnado ( $33 \%$ de las respuestas), al tener en su trabajo mayor exigencia laboral por disponibilidad de tiempo o exceso de actividades, lo que resulta incompatible con la continuidad de sus estudios. En segundo término, se mencionan condiciones de salud (15\%) incluyendo Covid-19 u otros padecimientos (cirugías, hospitalización o tratamientos largos). En tercer lugar, aparecieron condiciones familiares adversas (11\%) que implican el cuidado de familiares y responsabilidades de tiempo completo en el hogar.

Se manifiestan diversas situaciones de índole emocional $(11 \%)$, particularmente estrés, ansiedad o depresión, o se habla de desmotivación y estrés académico por la forma en que están vivenciando la enseñanza en pandemia, así como por la reducción del semestre $(9 \%)$. Se manifiesta inconformidad con las condiciones de la docencia y el aprendizaje en línea $(6 \%)$ o con la infraestructura y acceso a las TIC que tienen, ya que resulta obsoleta, deficiente o incosteable $(5 \%)$. Para algunos, el problema es la discontinuidad previa en su trayectoria escolar $(10 \%)$, es decir, desde el punto de vista administrativo, el rezago académico y la condición de alumno irregular respecto a la trayectoria curricular esperada los ubica en los límites temporales máximos para poder continuar inscritos. Otros más mencionaron estar cursando otra carrera de forma simultánea; les resulta muy complicado ajustarse a las demandas académicas en ambas, más todavía en "las condiciones actuales". En varios casos deciden acogerse al artículo referido en la legislación universitaria para no agotar su tiempo curricular "mientras las cosas mejoran". 

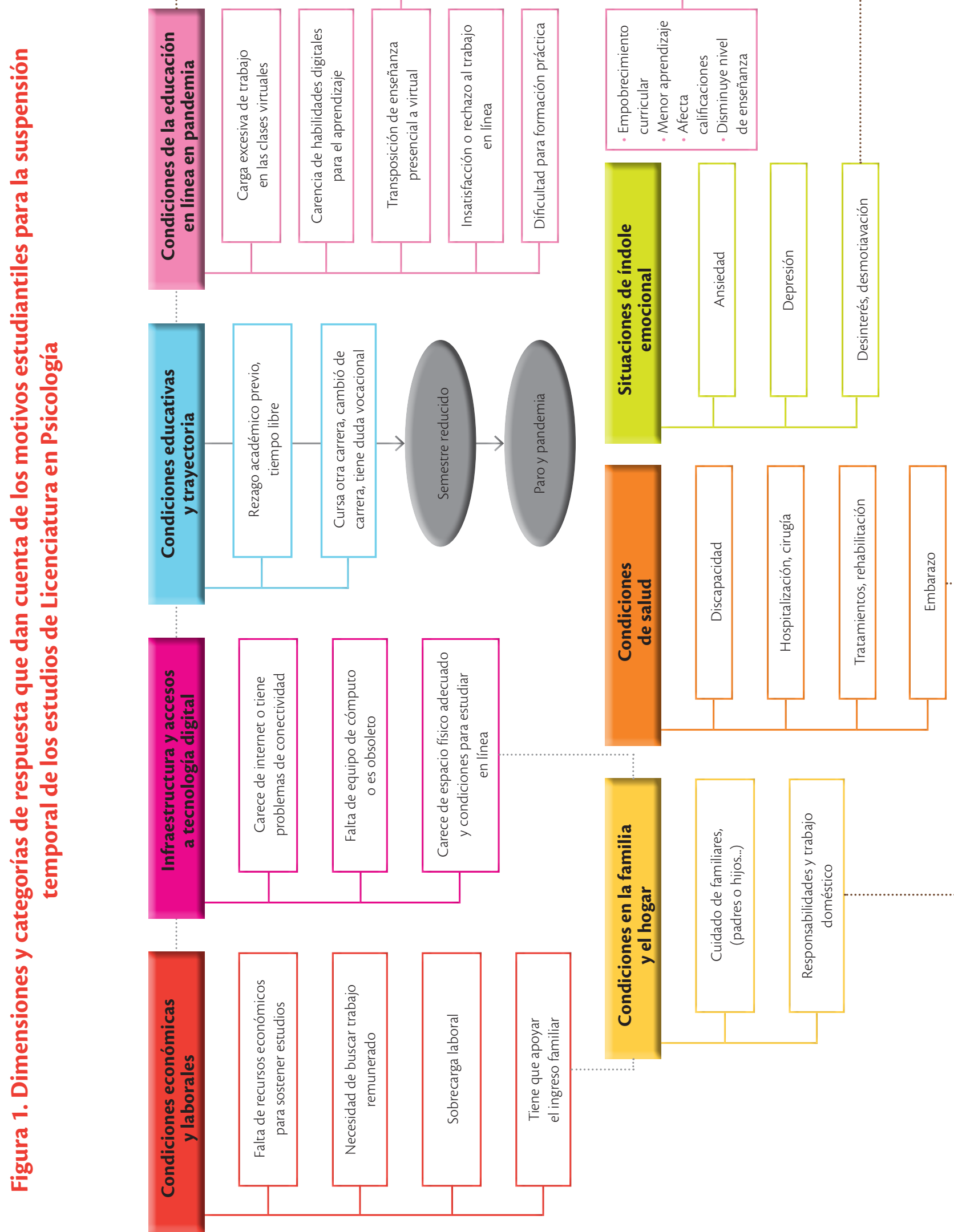


\section{Gráfica 5. Principales motivos de suspensión temporal de estudios}

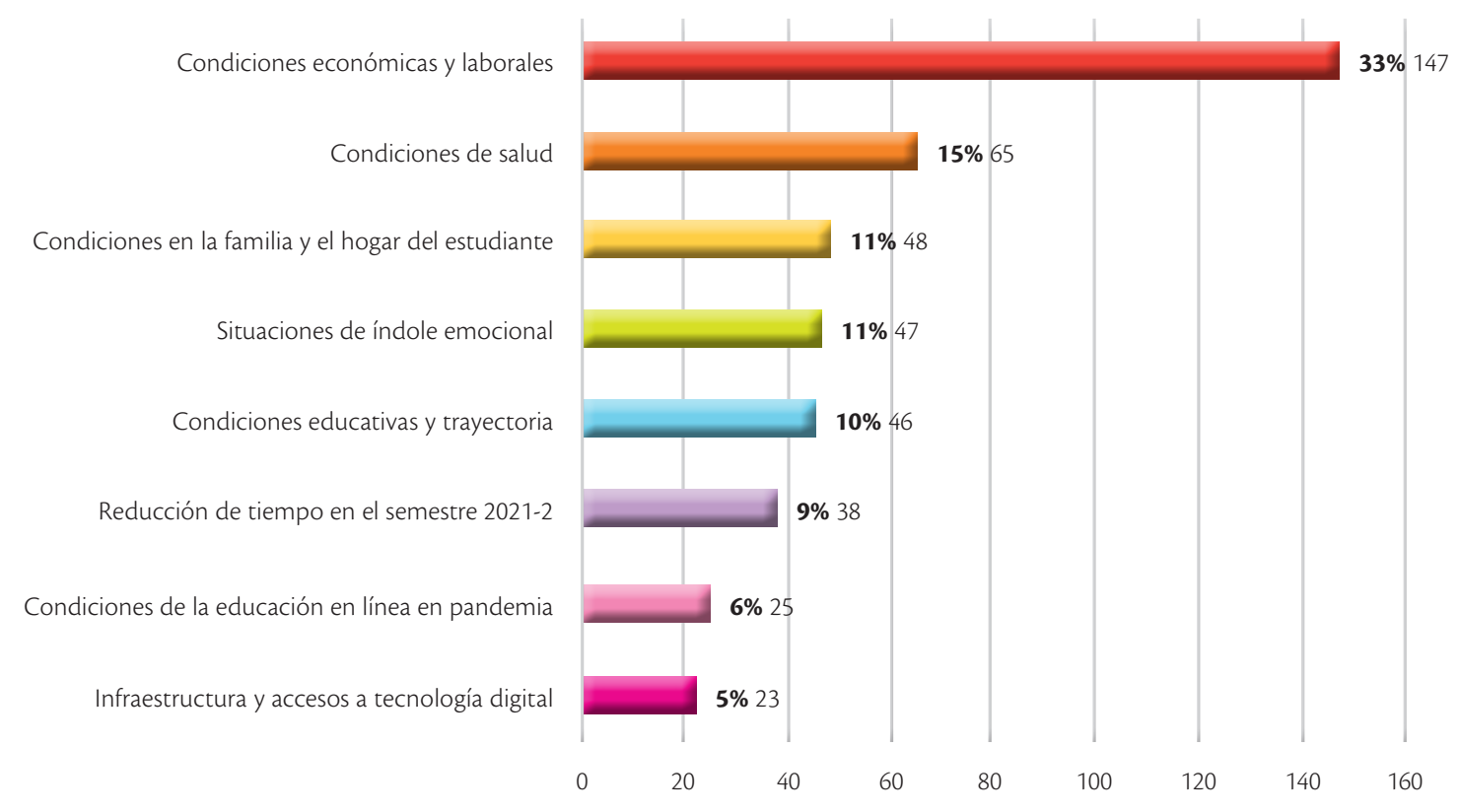

Fuente: elaboración propia con base en la investigación.

Se identificó a los y las estudiantes que mencionaron explícitamente que pedían suspensión temporal debido a la pandemia o al Covid-19 ("Por la pandemia mis papás se quedaron sin trabajo y tuve que aumentar mis horas de trabajo que interfieren con el horario académico", S139); un 36\% mencionó directamente dicha condición como factor causal, a la que atribuyen la necesidad de interrumpir sus estudios. En otros casos, mencionaban los eventos vinculados a los dos paros de clases que se han realizado en la entidad que, asociados a los eventos de la pandemia y sus consecuencias, les impiden la dedicación y aprendizajes deseados en la licenciatura
("Paro estudiantil y pandemia", S93). Algunos estudiantes, sin poner explícitamente los términos, indicaban problemas que se asocian a la pandemia o que se han acrecentado durante la misma: el 64\% se refieren directamente a las consecuencias o a situaciones que están enfrentado recientemente:

Ya que, debido a esta situación, mi familia no está bien económicamente y me gustaría poder ayudar$\operatorname{los}(\mathrm{S} 141)$.

Dada la situación de las clases en línea he dejado de disfrutar y perder la motivación por seguir estudiando (S156). 


\section{Condiciones socioeconómicas y falta de acceso a infraestructura y tecnología digital}

Las condiciones socioeconómicas y laborales de los estudiantes y sus familias resultaron las más críticas y fueron un factor determinante para tomar la decisión de interrumpir los estudios; además, parecen desencadenar o relacionarse con diversas situaciones que comprometen la salud y el bienestar emocional de los implicados. Ya se dijo que el 33\% de los estudiantes solicitan baja temporal debido a motivos asociados a dificultades económicas, ya sea que las presentaban previamente o se agudizaron en la pandemia por la pérdida de empleo en la familia, fallecimiento de proveedor, necesidad de buscar trabajo o porque las exigencias laborales se vieron intensificadas.

La situación económica de mi familia es crítica debido a que mi mamá perdió su trabajo [...] por tal motivo quiero apoyar a mi familia (S124).

Por la pandemia, en mi trabajo salgo tarde por cargas de trabajo, a veces debo cubrir guardias en fin de semana (S139).

Debido a las restricciones económicas, los y las estudiantes enfrentan problemas para tener las condiciones mínimas para estudiar, principalmente el acceso a los servicios digitales, que les resultan incosteables, porque su equipo es obsoleto o la zona donde viven no capta bien la señal de internet.

La falta de un sitio adecuado para estudiar en mi casa (S9).

La computadora que tenemos es bastante vieja, por lo que suele trabarse, además de que no contamos con los medios económicos para comprar una nueva o ir a un café internet (S15).

Vivo en el Estado de México y no cuento con los recursos para continuar con mis estudios virtualmente: mi internet falla constantemente (aún más cuando llueve) (S106).
Asociado a lo anterior, la dinámica familiar ha tenido que cambiar, por lo que han sumado las responsabilidades y las tareas domésticas o de cuidado familiar que tienen que asumir, incluso para que otros pudieran dedicarse al trabajo remunerado.

Es decir, son varios factores interdependientes, concatenados que se van sumando a una situación problemática que plantea otras prioridades por encima de los estudios universitarios.

\section{Condiciones de salud y situación socioemocional del estudiantado}

Si se conjuntan las situaciones que vulneran la salud con las condiciones emocionales que nos hablan de malestar en los y las estudiantes o en sus familiares, el 26\% de motivos para suspender los estudios indica la presencia de problemas físicos de consideración y reporte de alteraciones emocionales como ansiedad, depresión o estrés, que en unos cuantos casos han requerido hospitalización o medicación. Ya sea que fueran problemas que presentaban anteriores a la pandemia, o que aparecieron y se intensificaron en el transcurso del 2020 y 2021, han afectado a esta población al grado de representar un serio obstáculo para continuar con sus estudios y un riesgo para su estabilidad y bienestar.

He presentado algunos problemas de salud (migraña crónica) que se complicaron por falta de atención médica debido a la contingencia sanitaria, los cuales debo atender para recuperarme y mejorar mi rendimiento académico (S17).

Debido a que por la situación y otros asuntos personales se elevaron mis niveles de ansiedad lo que no me permitió llevar el ritmo para realizar las actividades de las materias que inscribí (S77).

El año pasado 2020 generé adicción a distintas sustancias, me volví adicta, pedí ayuda en Centro de Integración Juvenil AC donde me van a atender ya que mi vida se ha complicado por esta situación, quiero enfocarme en mi rehabilitación total (S143). 


\section{Condiciones educativas en la entidad y trayectoria previa del alumnado}

Se ha comentado que suelen resultar incompatibles los planes y ritmos de trabajos o condiciones para estudiar de algunos estudiantes con la normativa y tiempos que fijan las instituciones escolares. Si la trayectoria previa no se ajusta a la esperada o teórica en el plan de estudios o no es acorde a los tiempos pautados, se producen discontinuidades que pueden provocar la suspensión de estudios. Asimismo, la posibilidad de cursar simultáneamente dos carreras resulta compleja para muchos estudiantes.

Es mi último semestre adicional y la última oportunidad que tengo para completar mis créditos [...] creo que podría aprovechar más mi último semestre cuando todo mejore (S44).

Actualmente me encuentro en la pasantía de Medicina, por eso quiero suspender un semestre (S45).

En no pocos casos los y las estudiantes se mostraron inconformes con la gestión administrativa (inscripciones, horarios, trámites) y más todavía con el ajuste al calendario escolar que restringió significativamente el número de semanas para el periodo 2021-2. Ante esto, sus motivos para suspender estudios se refieren a la baja calidad en la formación que recibirán en tan pocas semanas, a la manera en que esto generará tensiones que los afectarán en el aprendizaje y emocionalmente. Para otros, la formación para la profesión requiere tomarse en la modalidad presencial, por la posibilidad de asistir a prácticas o laboratorios.

Este semestre contemplaba realizar prácticas que me ayudarían a consolidar mis conocimientos respecto al área de mi interés, por ende, encuentro carente de sentido tomar dicho semestre en un periodo corto de tiempo y que además será cursado a distancia (S188).
Tengo problemas con mi salud mental desde hace un tiempo, afecta mi desempeño académico, puede empeorar por el nuevo calendario. Quiero tener el semestre completo con la esperanza de que en un año sea en presencial (S198).

Tal como se ha encontrado en los estudios ya referidos en la revisión de literatura de este artículo, muchos estudiantes se muestran insatisfechos, poco motivados y con falta de adaptación a la modalidad educativa en línea. Ello es debido a una inadecuada trasposición didáctica de la educación presencial a la virtual, puesto que se trata de sistemas de actividad distintos, donde tienen que preverse los componentes y dinámica en cuestión de los respectivos ambientes de aprendizaje.

Respecto a la insatisfacción con el trabajo académico en línea ( $6 \%$ de motivos), hay que indagar ulteriormente si se debe a la carencia tanto de habilidades para el aprendizaje en línea como de estrategias de autoestudio, a la preferencia y familiaridad con las actividades presenciales o al manejo didáctico en los cursos. En diversos casos aparece la percepción de que se ha dado una reducción y empobrecimiento curricular debido a la enseñanza en línea, que se aprende menos, que no se están adquiriendo competencias para la profesión y que se carece de formación en la práctica.

Se asignaban muchas plataformas para trabajar en línea, mala planeación de trabajo en línea, falta de motivación para esa modalidad de trabajo (S71).

$\mathrm{Al}$ ser mis semestres de prácticas siento constantemente que no me estoy acercando a la práctica profesional (S123).

Los horarios ofertados no me parecen buenos, no logré inscribir las materias que eran de mi interés. Mi rendimiento escolar ha disminuido bastante desde el inicio del semestre en línea por lo que he decidido no cursar un tercer semestre de forma virtual (S142). 


\section{Diferencias respecto al género y modalidad educativa}

Con base en los resultados de una encuesta con 12 158 universitarios de la UNAM, Infante-Castañeda, Peláez-Ballestas y Giraldo-Rodríguez (2021) encuentran una mayor afectación de la pandemia en la población femenina, sobre todo en la salud mental y debido a la sobrecarga de trabajo doméstico, cuidado de la casa y familia, que evidencian la inequidad de género y la prevalencia de mandatos de género patriarcales. En el caso de las estudiantes de psicología, los datos parecen coincidir con las tendencias apuntadas en la encuesta mencionada. En nuestro caso, al parecer los hombres (74\%) están más presionados por las condiciones económicas y laborales que las mujeres $(30 \%)$, pero en las mujeres hay una afectación mayor en el plano emocional $(13 \%)$ en comparación a los varones $(8 \%)$. Aunque ambos aducen que tienen que atender condiciones familiares (14\% hombres, 12\% mujeres), el análisis cualitativo indica que son más las mujeres que hablan de dedicarse al cuidado de los hijos, de familiares enfermos y de adultos mayores, así como al apoyo en labores del hogar, como es el caso de las siguientes alumnas:

Al ser mi hermano y cuñada médicos y tener exceso de trabajo durante la contingencia, yo me he hecho cargo del cuidado de mi sobrino de 4 años desde marzo, con el cual, tengo que entrar a clases de 9 a 1, preparar la comida diaria y limpiar la casa, por lo cual no tengo tiempo para tomar el semestre (S20).

Me encuentro sola con mi hija de 3 años haciendo home office, es demasiada la carga de trabajo entre los quehaceres del hogar, el cuidado de mi hija y los compromisos laborales con los que tengo que cumplir, ha sido prácticamente imposible dedicarme a mis estudios (S27).
Por otro lado, son los varones quienes se muestran más inconformes con las condiciones educativas prevalecientes y la docencia en línea $(5 \%$ mujeres, $11 \%$ hombres), así como con la reducción del actual semestre (21\% hombres y $7 \%$ mujeres). Consideramos que se requieren estudios más específicos para ahondar en la situación de género en pandemia en esta población y en nuestra entidad (véase gráfica 6).

Finalmente, se contrastaron los motivos expresados por los alumnos del sistema escolarizado y los del sistema de universidad abierta. En la gráfica 7 se observa que en ambas modalidades el factor que más incide en las suspensiones es de índole económica y laboral, con una tendencia a ser más mencionado por estudiantes del sistema abierto (38\%) que del escolarizado (31\%). Respecto a las condiciones de salud, familiares y emocionales de los estudiantes, éstas se distribuyen en proporciones relativamente similares en ambos grupos, aunque parece que con mayor afectación en los del sistema escolarizadopresencial (8\% contra 12\%). Los alumnos de la modalidad presencial reportan más conflictos por la reducción del semestre 2021-2, insatisfacción con la educación en línea recibida, así como malas condiciones de infraestructura y acceso a la tecnología digital. Parece ser que les ha afectado más el tránsito a la virtualidad, por la falta de condiciones y previsión institucional, la carencia de formación de los docentes, la sensación de estar aprendiendo menos o de pérdida de la formación en la práctica y de competencias para la profesión que asocian a la presencialidad y a la asistencia a escenarios profesionales. Habrá que ahondar en qué medida los estudiantes de la modalidad presencial consideran que el mayor problema es el no estar preparados para la educación en línea o la percepción negativa que tienen de dicha modalidad y si de ello depende la dificultad para adaptarse y sentir disposición por aprender en las clases virtuales. 
Trayectorias interrumpidas: motivos de estudiantes universitarios para suspender...

\section{Gráfica 6. Motivos de suspensión temporal de estudios por sistema escolarizado/abierto}

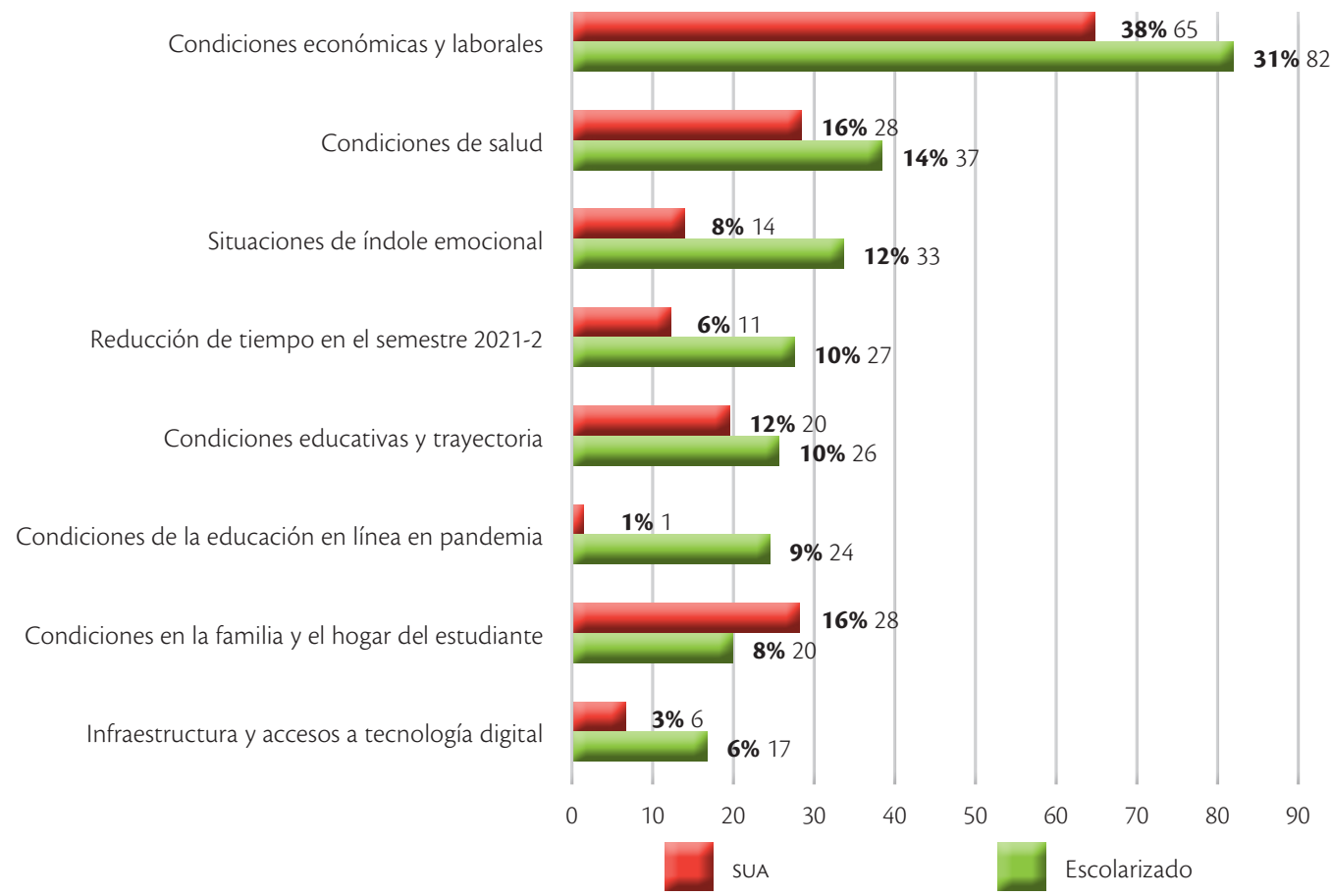

Fuente: elaboración propia con base en la investigación.

\section{Gráfica 7. Motivos de suspensión temporal en función del sexo}

Condiciones económicas y laborales

Condiciones de salud

Situaciones de índole emocional

Condiciones en la familia y el hogar del estudiante

Condiciones educativas y trayectoria

Reducción de tiempo en el semestre 2021-2

Infraestructura y accesos a tecnología digital

Condiciones de la educación en línea en pandemia
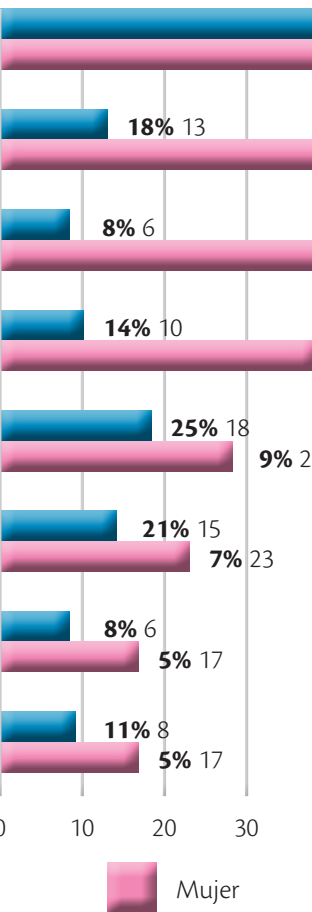

$74 \% 53$

$17 \% 52$

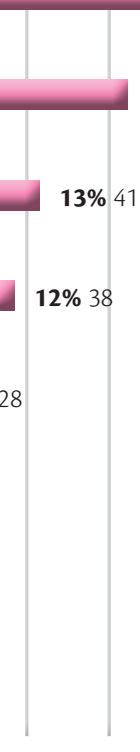

$12 \% 38$

$9 \% 28$

50

$60 \quad 70$

$80 \quad 90$

100 


\section{Conclusiones}

$\mathrm{El}$ análisis presentado logró identificar los principales factores vinculados a la posibilidad de dar continuidad o interrumpir la trayectoria escolar de los estudiantes de la licenciatura en Psicología de la Facultad de Psicología de la UNAM, a partir de analizar los motivos que conducen a un sector a solicitar suspensión de estudios durante la pandemia. En los últimos semestres esta entidad universitaria se ha visto involucrada en dos paros prolongados (uno por motivos de violencia de género y el otro por la falta de pago a los docentes de asignatura) en el marco del confinamiento debido a la pandemia por Covid-19, estos hechos se han conjuntado con una diversidad de situaciones personales, familiares, académicas y socioeconómicas. Reconocer la relevancia de estos factores desde la propia voz del alumnado puede contribuir a la planeación de acciones de seguimiento a las trayectorias estudiantiles, de apoyo tutorial y a programas de formación más efectivos enmarcados en su realidad y necesidades.

Es importante propiciar el retorno de estos jóvenes a sus estudios de licenciatura, así como tomar medidas preventivas para que no se siga incrementando el número de quienes tienen que suspender sus estudios sea temporal o definitivamente. Sin embargo, coincidimos en que "no se trata de normalizar las trayectorias, sino de ofrecer una amplia gama de trayectorias educativas diversas y flexibles" (Terigi, 2007: 18). Los datos del estudio permiten cuestionar la idea de uniformidad en el perfil ideal del estudiantado universitario y reconocer que la discontinuidad en las trayectorias escolares obedece a una diversidad de factores de carácter sistémico y contextual, no sólo personales. Reiteramos la importancia que tiene priorizar una mirada subjetiva, personalizada y sobre cada alumno/alumna, sobre todo en lo que atañe a la tutoría y acompañamiento que sería viable ofrecer a nivel institucional, con sustento en los preceptos de la educación inclusiva.

La conclusión principal es que la población estudiantil analizada en este trabajo se encuentra en una evidente situación de vulnerabilidad, en el sentido planteado por CEPAL-UNESCO (2020). Los y las estudiantes que han suspendido sus estudios están en el grupo de riesgo de retroceso en el desarrollo humano de las personas, y no hay seguridad de que tal suspensión sea temporal o definitiva a menos que se eliminen las barreras que han conducido a la discontinuidad escolar. Dado que el desarrollo humano se estima en función del nivel de ingreso, la salud y la educación a los que se tiene acceso, encontramos que los tres factores están afectando a la mayoría de estos jóvenes. La posibilidad de seguir adelante con el proyecto de carrera que se han trazado se encuentra en riesgo, y la educación universitaria como posibilidad de un mejor futuro en la lógica de un ejercicio profesional competente, una adecuada inserción laboral y la mejora de sus condiciones de proyecto de vida, resulta cuestionada a la luz de lo que han vivenciado en pandemia.

En la pandemia se desencadenó un contexto complejo de procesos que suceden simultáneamente y que interactúan generando consecuencias directas e indirectas que resultan abrumadoras y afectan la vida cotidiana y académica de los y las estudiantes. En primer lugar, en el estudio aparecieron los factores materiales (económicos y laborales) que son básicos para el sostenimiento de las y los estudiantes y que pueden influir en el resto de los factores detectados, al desencadenar o complejizar otras problemáticas que conducen a suspender los estudios. Las restricciones materiales que se expresan por una condición económica precaria y se asocian con la falta de recursos económicos e infraestructura para el estudio que son elementales para la actividad académica en general, y particularmente para la educación en línea, operaron de manera significativa para que muchos de los estudiantes tuvieran que suspender sus estudios y salir al campo laboral. En coincidencia con la literatura revisada, podemos decir que aquí opera la desigualdad económica del sistema, que condujo a muchos estudiantes de diversos niveles educativos, 
y sobre todo de escuelas y universidades públicas, a descontinuar sus estudios, dada la carencia de apoyos y medidas preventivas.

Otra dimensión fundamental son las condiciones de salud de los y las estudiantes e inclusive de sus seres más cercanos. Un número importante de estudiantes mencionaron que sus familiares enfermaron o incluso fallecieron de Covid-19 o que ellos se encontraban con afecciones en la salud y estado emocional. La ansiedad, la depresión y el estrés, así como la condición de estar en duelo en las familias, llegaron a afectar de manera directa el rendimiento académico de los y las estudiantes y su misma disposición frente a la continuidad de los estudios universitarios. Esta situación, desafortunadamente común con lo encontrado en otros países, ha llevado a distintos organismos internacionales y locales a priorizar medidas de atención explícita al bienestar emocional y al tejido social en los contextos educativos, en particular, en el caso de las mujeres, los y las adolescentes y aquellos educandos con factores de riesgo o vulnerabilidad.

El compromiso y motivación de los estudiantes frente a las actividades académicas y su trayectoria de formación se entrecruza en algunos casos con las condiciones de impartición de clases virtuales que perciben deficientes, aunadas a la falta de familiaridad con el trabajo en línea, que les representa inclusive un vacío en los vínculos sociales e identitarios con la comunidad educativa de referencia. El alumnado de la Facultad de Psicología que decidió suspender sus estudios parece percibir que no está consolidando las metas de una formación profesional de calidad y por ende han perdido la motivación, consideran que están aprendiendo muy poco, que se carece de formación práctica, que "todo es teórico", que sus expectativas respecto a la profesión no se están cumpliendo y saldrán mal preparados, lo que los pondrá en desventaja en el campo laboral. Esto genera gran incertidumbre frente a su futuro, aunado a los riesgos en su salud percibidos.
En coincidencia con el estudio de González-Velázquez (2020), es probable que el alumnado universitario esté enfrentando un alto nivel de estrés académico, ya que la pandemia ha generado no sólo encierro forzado para muchos jóvenes, sino desorganización en el estudio, alteración de rutinas y espacios académicos, aunada a la percepción de pérdida de control y de capacidad de autorregulación, por lo que se intensifican emociones y pensamientos negativos. Coincidimos con la autora en sugerir la identificación de factores protectores y el fortalecimiento de la resiliencia académica y afectiva, mediante estrategias de afrontamiento activo y acompañamiento, además de un necesario replanteamiento del modelo educativo universitario, acorde a la llamada nueva normalidad. Nuestros resultados también coinciden con el estudio de Lozano-Díaz et al. (2020), porque se encuentra que el impacto de la pandemia en la población universitaria se asocia a tres aspectos: el capital social del alumnado en riesgo de abandono, su capacidad de resiliencia a nivel académico y psicológico, así como la (in)satisfacción vital reportada en salud, ingresos o trabajo. Estos autores también abogan por la formación de redes de apoyo y tutoría, el fomento de la resiliencia y diversas estrategias para abordar situaciones de crisis en el propio contexto universitario. No se trata del problema personal de estudiantes aislados, sino de situaciones sistémicas propias del sistema educativo, que deben atenderse con políticas institucionales con carácter interseccional.

Por ende, la Facultad de Psicología, en conjunción con una serie de programas y políticas emprendidas en la universidad, requiere crear y fortalecer apoyos a la recuperación y continuidad de las trayectorias del estudiantado, basadas en el conocimiento de su problemática y necesidades. Los obstáculos mencionados por el estudiantado y la toma de decisiones institucional frente a los cambios que implica la transposición de lo presencial a lo virtual, y ante el regreso a la presencialidad o a un modelo hibrido, definirán la continuidad o suspensión de los estudios de muchos más estudiantes de esta licenciatura. 
La población en cuestión no ha sido objeto de seguimiento ni apoyo tutorial, probablemente no están enterados de distintas opciones que se han ofrecido en la universidad para el apoyo en el acceso a equipo de cómputo e internet ni a los servicios existentes de apoyo psicológico en la propia entidad. Su condición de alumnado en situación "irregular" cancela la posibilidad de acceder a becas, lo que aumenta las restricciones económicas que ya padecen. Proponemos que se tomen en cuenta los factores aquí identificados como factores de riesgo y a la par se dé oportunidad para la continuidad de la trayectoria académica de los y las estudiantes ofreciendo opciones más flexibles e inclusivas.

La perspectiva de los y las estudiantes respecto a la docencia que se está impartiendo en línea, representa la posibilidad de interpelar y mejorar dicha docencia y sus condiciones de impartición en la licenciatura y en sus dos sistemas, abierto y presencial. Esto permitirá la mejora de los cursos que se imparten a partir de la comprensión y puesta en práctica de entornos de aprendizaje virtual, híbrido o presencial pertinentes, considerando asimismo la revisión de los programas de asignaturas que fueron pensados en conjunto para una enseñanza presencial en la lógica de una normalidad pre-pandemia. Los retos en la formación del psicólogo y la diversificación de estrategias, materiales educativos, escenarios y métodos de trabajo, requieren adecuarse a la realidad que está viviendo hoy en día la educación universitaria y la psicología como profesión. Habrá que explorar si el mayor descontento que muestran los alumnos del sistema escolarizado en contraste a los que cursan el sistema abierto y a distancia, se debe a que estos últimos tienen más recursos tanto académicos como de infraestructura y se encuentran habituados o con más fortalezas y apoyos para trabajar en esta modalidad.

$\mathrm{Al}$ mismo tiempo, habrá que repensar los servicios de gestión escolar en lo que atañe a su contribución como apoyos a la consolidación de las trayectorias académicas (gestión eficiente del servicio social, titulación, inscripciones, opciones de recursamiento, horarios flexibles, entre otros). La gestión universitaria no puede quedarse anquilosada en prácticas e instrumentos de control y certificación burocráticos y propios del siglo antecedente.

Por otro lado, debe reconocerse que la educación mediada por TIC seguirá expandiéndose en los contextos universitarios, y que la universidad más importante del país no puede quedar a la zaga; hace falta un programa institucional que permita innovar la docencia y los procesos de gestión escolar con la mediación de las tecnologías digitales más avanzadas. La profesión psicológica, como muchas otras, deberá incorporar la formación en competencias para los retos del siglo XXI lo que al parecer no se está logrando en esta entidad, por lo menos en la población que argumenta no consolidar el aprendizaje de la profesión en la virtualidad ni disponer de tecnologías digitales, o no encontrarles sentido para el ejercicio profesional del psicólogo.

Por otro lado, las tecnologías no son fines en sí mismas ni se trata de que sigan proliferando cursos técnicos centrados en aplicaciones informáticas desvinculados de la formación universitaria. Al respecto coincidimos con Ángel Díaz Barriga (2021: 3) cuando afirma que la universidad debe realizar cambios estructurales, no pensar que basta con incorporar tecnologías digitales "sin analizar las razones por las que las clases expositivas permanecen en sus aulas". Es decir, se requieren innovaciones disruptivas en la formación del profesional de la psicología, tanto en las prácticas formativas como en las competencias para la acción profesional con sentido y pertinencia social.

Otro ángulo del problema consiste en recuperar la vivencia de los docentes. Es probable que ellos también enfrentaran falta de familiaridad y competencia con la gestión y diseño de actividades académicas con la mediación de TIC. Esto llevó a un traslado mecánico del espacio educativo 
presencial al virtual, sin conocer o tomar en cuenta la diferencia y complejidad de los ambientes virtuales de aprendizaje. Esto ha repercutido en una carga excesiva de trabajo para los estudiantes y es posible que también para muchos docentes. Habrá que derivar acciones expeditas y apropiadas en función de

\section{Agradecimientos}

- Al apoyo de la DGAPA, Universidad Nacional Autónoma de México (UNAM), a través del proyecto PAPIIT IN301620.

- A los comentarios y sugerencias de Hortensia García Vigil, Elisa Saad Dayán y Georgina Delgado, académicas de la Coordinación de Psicología de la Educación, Facultad de Psicología, UNAM.

- Al apoyo de los consejeros técnicos de la Facultad de Psicología, UNAM, interesados en la mejora de las condiciones de la población estudiantil, en particular a Iván Palacios.

\section{Referencias}

Barrón, Concepción y Frida Díaz-Barriga (2016), "Curriculum management and the role of curriculum actors", Transnational Curriculum Inquiry (TCI), vol. 13, núm. 2, pp. 13-33, <https://ojs.library.ubc.ca/index.php/tci/ article/view/188285> [Consulta: junio de 2021].

Briscioli, Bárbara (2017), "Aportes para la construcción conceptual de las trayectorias escolares", Revista Actualidades Investigativas en Educación, vol. 17, núm. 3, pp. 1-30, <https://revistas.ucr.ac.cr/index.php/aie/ article/view/30212> [Consulta: junio de 2021].

Casal, Joaquim, Maribel García, Rafael Merino y Miguel Quesada (2006), "Itinerarios y trayectorias. Una perspectiva de la transición de la escuela al trabajo", Trayectorias, año VIII, núm. 22, septiembrediciembre, pp. 9-20, <https://www.researchgate.net/ publication/48168971_Itinerarios_y_trayectorias_ las necesidades de distintos claustros académicos, que incidan en la mejora en lo que atañe a la modalidad en línea, en anticipación a un reto que se avecina, la instrumentación del modelo híbrido y en su momento, la nueva normalidad en la enseñanza presencial de las profesiones universitarias.

Una_perspectiva_de_la_transicion_de_la_escuela_al_ trabajo > [Consulta: noviembre de 2021].

CEPAL-UNESCO (2020), "La educación en tiempos de pandemia del COVID-19", Santiago de Chile, Oficina Regional de Educación para América Latina y el Caribe, <https://www.cepal.org/es/publicaciones/45904-laeducacion-tiempos-la-pandemia-covid-19> [Consulta: junio de 2021].

Corporación Andina de Fomento Educativo (2019), "Cerrar la brecha digital en América Latina y el Caribe depende críticamente de la transformación de los Fondos de Servicio Universal", <https://www.caf.com/es/ actualidad/noticias/2019/07/cerrar-la-brecha-digitalen-america-latina-y-el-caribe-depende-criticamente-dela-transformacion-de-los-fondos-de-servicio-universal> [Consulta: junio de 2021].

Creswell, John y Vicki Plano-Clark (2018), Mixed methods research (Third edition), Los Angeles, CA., SAGE Publications.

Cuenca, Ricardo (2012), "Sobre justicia social y su relación con la educación en tiempos de desigualdad", Revista Internacional de Educación para la fusticia Social, vol. 1, núm. 1, pp. 79-93, <http://www.rinace.net/riejs/numeros/ vol1-num1/art3.pdf> [Consulta: junio de 2021].

Díaz-Barriga, Ángel (2021), "Repensar la universidad: la didáctica una opción para ir más allá de la inclusión de tecnologías digitales", Revista Iberoamericana de Educación Superior (RIES), vol. 34, núm. 12, pp. 3-20, <https:// www.ries.universia.unam.mx/index.php/ries/article/ view/976> [Consulta: junio de 2021]. 
Díaz-Barriga, Frida, José Luis López y Edmundo López (2020), "Trayectorias personales de aprendizaje y currículo flexible: la perspectiva de los estudiantes universitarios de psicología", Revista Iberoamericana de Educación Superior (RIES), vol. 11, núm. 30, pp. 3-21, <https://www.ries.universia.unam.mx/index.php/ries/ article/view/585/1237> [Consulta: junio de 2021].

Echeita, Gerardo (2020), "La pandemia del COVID-19. ¿Una oportunidad para pensar en cómo hacer más inclusivos nuestros sistemas educativos?", Revista Internacional de Educación para la fusticia Social, vol. 9, núm. 1, pp. 7-16, <https://revistas.uam.es/riejs/ article/view/12152> [Consulta: junio de 2021].

González-Velázquez, Lilia (2020), "Estrés académico en estudiantes universitarios asociados a la pandemia por COVID-19", Revista ESPACIO I+D, Innovación más Desarrollo, vol. 9, núm. 25, pp. 157-179, <https:// espacioimasd.unach.mx/index.php/Inicio/article/ view/249/794> [Consulta: junio de 2021].

Instituto Nacional de Estadística, Geografia e Informática (INEGI) (2019), Encuesta Nacional sobre Disponibilidad y Uso de Tecnologías de la Información en los Hogares (ENDUTIH), México, INEGI, <https://www.inegi.org.mx/ programas/dutih/2019/> [Consulta: junio de 2021].

Infante-Castañeda, Claudia, Ingris Peláez-Ballestas y Liliana Giraldo-Rodríguez (2021), "COVID-19 y género: efectos diferenciales de la pandemia en universitarios", Revista Mexicana de Sociología, vol. 83, Número Especial. Efectos sociales por la pandemia de COVID-19, pp. 169-193, <http://revistamexicanadesociologia. unam.mx/index.php/rms/article/view/60072> [Consulta: junio de 2021].

Lozano-Díaz, Antonia, Juan Sebastián FernándezPrados, Victoria Figueredo-Canosa, y Ana María Martínez-Martínez (2020), "Impactos del confinamiento por el Covid-19 entre universitarios: Satisfacción Vital, Resiliencia y Capital Social Online", International fournal of Sociology of Education, Special Issue: Covid-19 Crisis and Socioeducative Inequalities and Strategies to Overcome them, pp. 79-104, <https://dialnet.unirioja.es/servlet/ articulo? codigo $=7495555>$ [Consulta: junio de 2021].
Moreno, Teresa (2020), “72 mil estudiantes de UNAM en riesgo de desertar por crisis", El Universal, <https:// www.eluniversal.com.mx/nacion/72-mil-estudiantesde-unam-en-riesgo-de-desertar-por-crisis $>$ [Consulta: septiembre de 2020].

Nicastro, Sandra y María Greco (2009), Entre trayectorias. Escenas y pensamientos en espacios de formación, Rosario, Argentina, Hommo Sapiens.

Pequeño, Ivana, Sebastián Gadea, Marcelo Alborés, Luciana Chiavone, Carolina Fagúndez, Silvia Jiménez y Ana Belén Santa Cruz (2020), "Enseñanza y aprendizaje virtual en contexto de pandemia. Experiencias y vivencias de docentes y estudiantes de la Facultad de Psicología en el primer semestre del año 2020”, Revista InterCambios, vol. 7, núm. 2, pp. 1-18, <http:/ / www.scielo.edu.uy/scielo.php?pid=S230101262020000200150\&script=sci_arttext $>$ [Consulta: noviembre de 2020].

Pérez-Mora, Ricardo y Carlos Iván Moreno (2021), "Percepciones de los estudiantes, desde su diversidad, sobre los efectos de la transición a la modalidad en línea en el marco de la pandemia COVID-19", Revista Iberoamericana de Educación, vol. 86, núm.1, pp. 147-169, DOI: https://doi.org/10.35362/rie8624444 [Consulta: diciembre 2021].

Programa de Naciones Unidas para el Desarrollo (PNUD) (2020), Desarrollo humano y COVID-19 en México. Desafios para una recuperación sostenible, PNUD en ReliefWeb, <https://reliefweb.int/report/mexico/desarrollohumano-y-covid-19-en-m-xico-desaf-os-para-unarecuperaci-n-sostenible> [Consulta: enero de 2021].

Reglamento General de Inscripciones de la UNAM (1997), consultado en Subdirección de Sistemas de Registro Escolar, <https://www.dgae-siae.unam.mx/acerca/ normatividad.html\#leg-3> [Consulta: mayo de 2020].

Ríos, Cecilia (2021), "Deserción escolar se dispara en la UNAM durante la pandemia", Milenio, <https://www. milenio.com/politica/comunidad/covid-pandemiadispara-desercion-escolar-unam $>$ [Consulta: mayo de 2021].

Román, José Antonio (2020), “El 67.3\% de alumnos 
de la UNAM no logra adaptarse a clases virtuales", La fornada, <https://www.jornada.com.mx/ultimas/ sociedad/2020/04/30/el-67-3-de-estudiantes-dela-unam-no-logra-adaptarse-a-clases-virtuales-9609. html\#: :text $=\mathrm{El} \% 2067.3 \% 20$ por $\% 20$ ciento $\% 20$ de,respondi $\% \mathrm{C} 3 \%$ B3 $\% 20$ que $\% 20$ les $\% 20$ imparten $\% 20$ clases> [Consulta: mayo de 2021].

Secretaría General de la UNAM (2020), Encuesta de Movilidad UNAM. Resultados Preliminares, México, UNAM, <https://www.iztacala.unam.mx/avisos_2020/ EncuestadeMovilidadUNAM_Resultadospreliminares. pdf> [Consulta: junio de 2021].

Terigi, Flavia (2007), "Los desafíos que plantean las trayectorias escolares", Conferencia presentada en el III Foro Latinoamericano de Educación Jóvenes y docentes. La escuela secundaria en el mundo de hoy, Buenos Aires,
Argentina, Fundación Santillana, 28 de mayo, <https:// filadd.com/doc/terigi-los-desafios-que-plantean-lastrayectorias> [Consulta: enero de 2021].

Toscano, Ana Gracia, Bárbara Briscioli y Aldana Morrone (2015), "Trayectorias escolares: estrategias teórico-metodológicas para su abordaje", Ponencia presentada en la XI Jornadas de Sociología, Argentina, Facultad de Ciencias Sociales, Universidad de Buenos Aires, <https://cdsa.aacademica.org/000-061/782. pdf> [Consulta: mayo de 2021].

UNESCO (2021), A un año del comienzo de la pandemia: continuidad educativa y evaluación en América Latina y el Caribe en 2021, Oficina Regional de Educación para América Latina y el Caribe de la UNESCO, <https://unesdoc. unesco.org/ark:/48223/pf0000377802> [Consulta: mayo de 2021].

\section{Cómo citar este artículo:}

Díaz-Barriga-Arceo, Frida, Javier Alatorre-Rico y Fernando Castañeda-Solís (2022), "Trayectorias interrumpidas: motivos de estudiantes universitarios para suspender temporalmente sus estudios durante la pandemia", Revista Iberoamericana de Educación Superior (RIES), vol. XIII, núm. 36, pp. 3-25, DoI: https://doi.org/10.22201/iisue.20072872e.2022.36.1181 [Consulta: fecha de última consulta]. 